\title{
Gastric perforation caused by secondary systemic amyloidosis
}

\author{
Hiroto Yamamoto ${ }^{1}$, Akihiko Yokota ${ }^{1}$, Noriyuki Suzuki ${ }^{1}$, Mitsuhiro Tachibana ${ }^{1}$, and Yutaka \\ Tsutsumi ${ }^{2}$ \\ ${ }^{1}$ Shimada Municipal Hospital \\ ${ }^{2}$ Pathos Tsutsumi
}

March 10, 2021

\begin{abstract}
An 82-year-old man, suffering abscess secondary to femoral prosthesis replacement, complained of intractable watery diarrhea and melena. Autopsy disclosed $12 \mathrm{~mm}$-sized perforation at the gastric prepylorus and purulent peritonitis. Amyloid A was deposited in systemic organs and tissues, including the site of gastric perforation. IgM was co-deposited in the glomeruli.
\end{abstract}

\section{Hosted file}

Gastric perforation caused by AA amyloidosis(including Tables).pdf available at https: //authorea.com/users/400548/articles/512852-gastric-perforation-caused-by-secondarysystemic-amyloidosis 


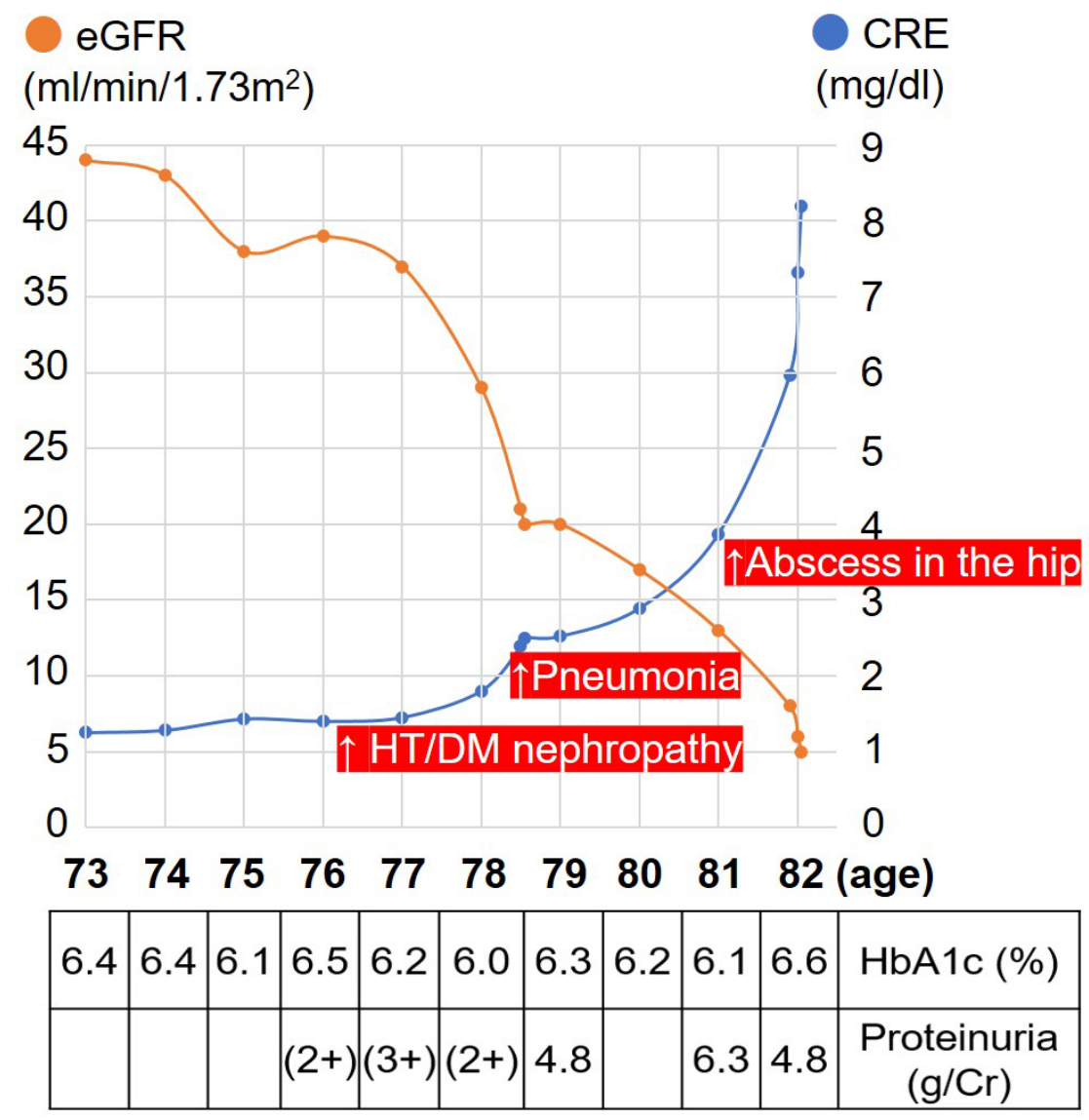




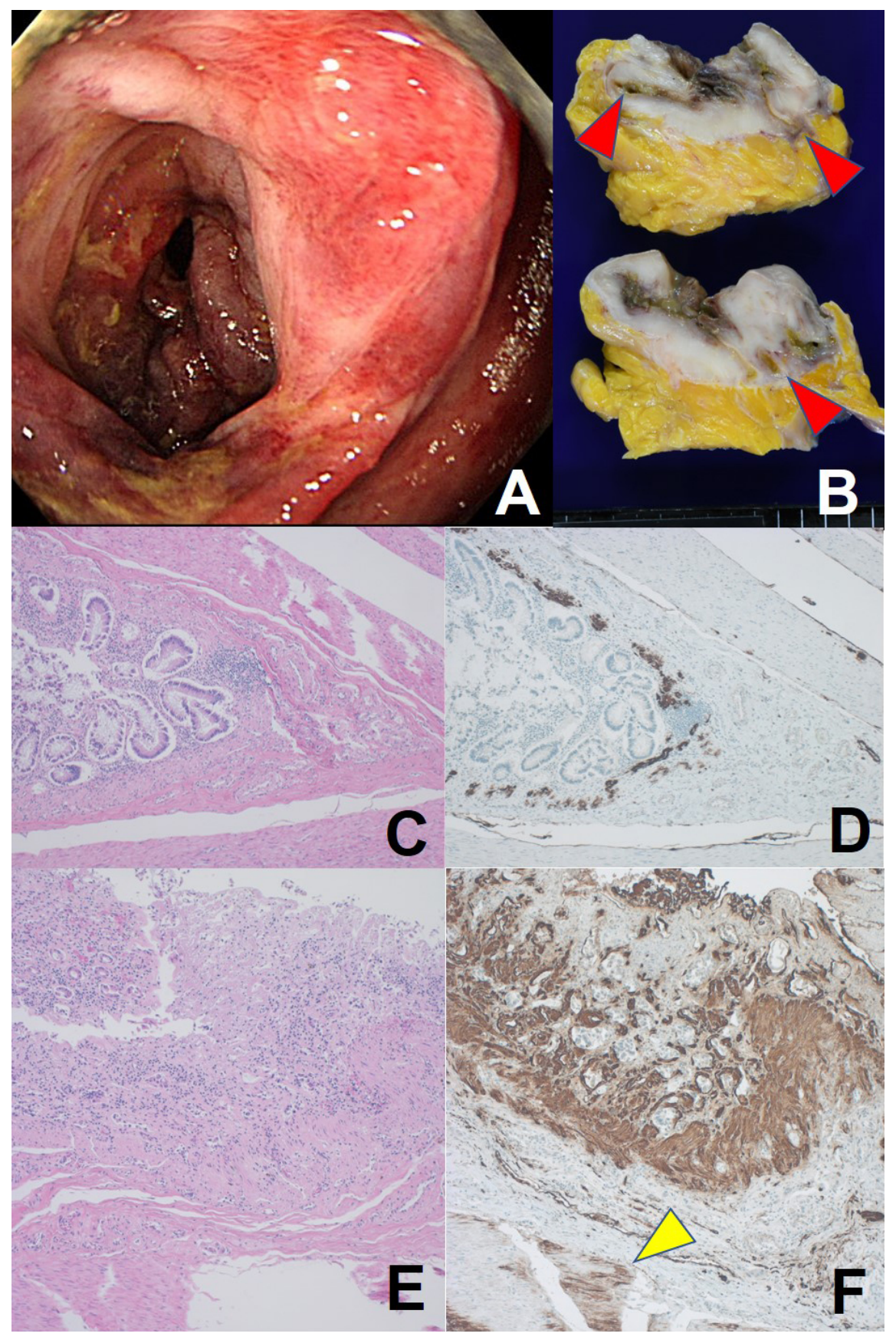




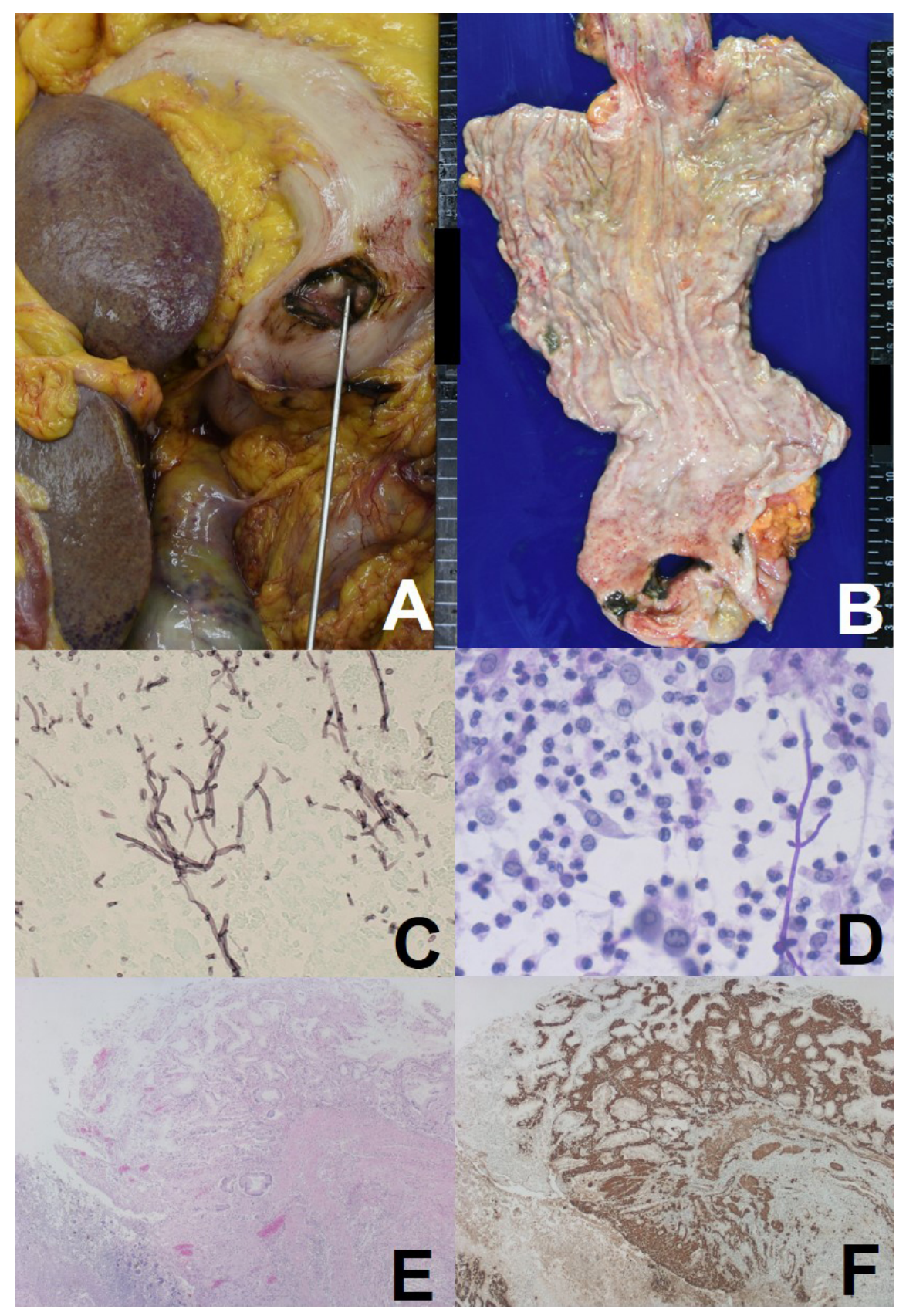



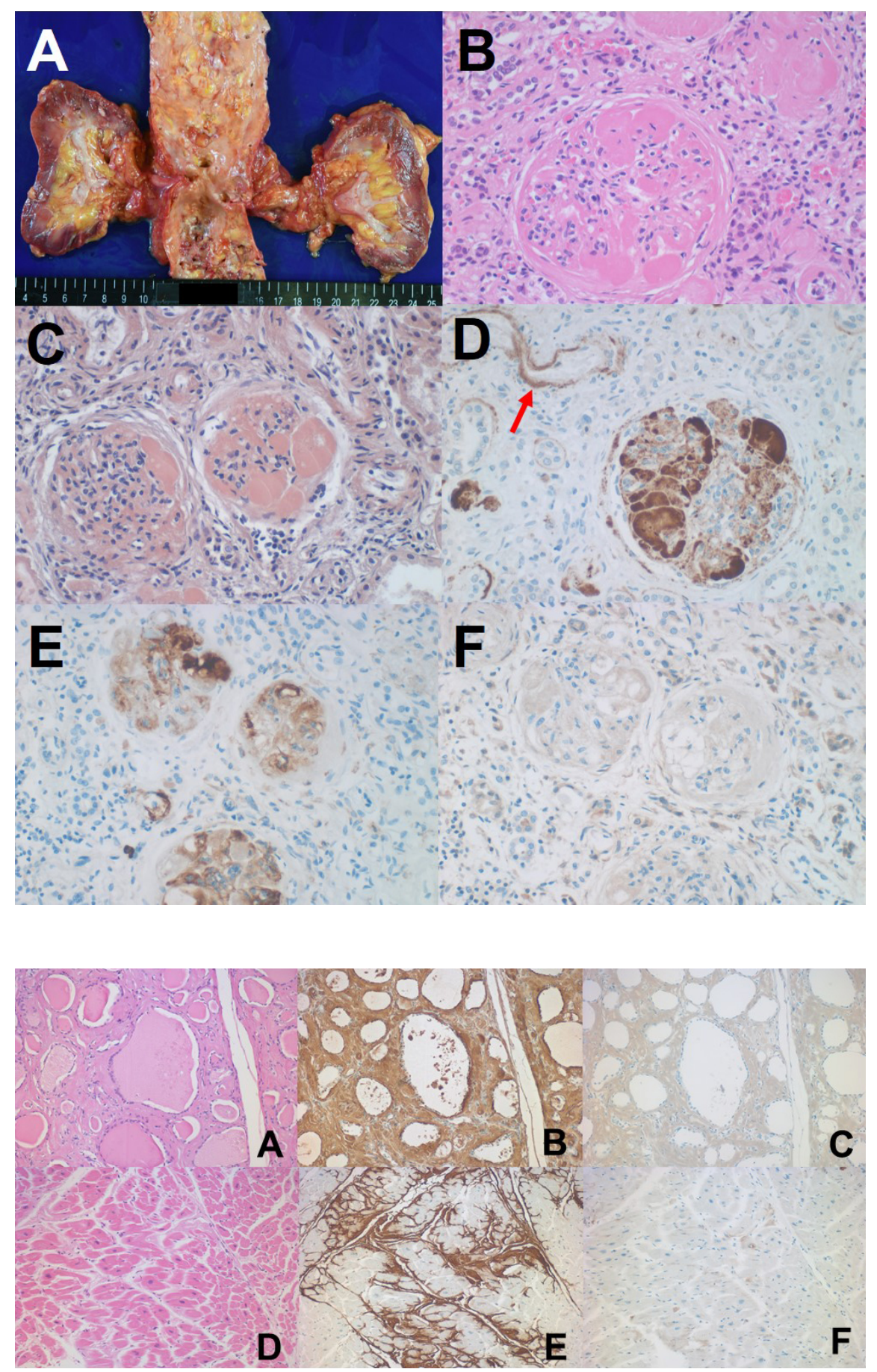


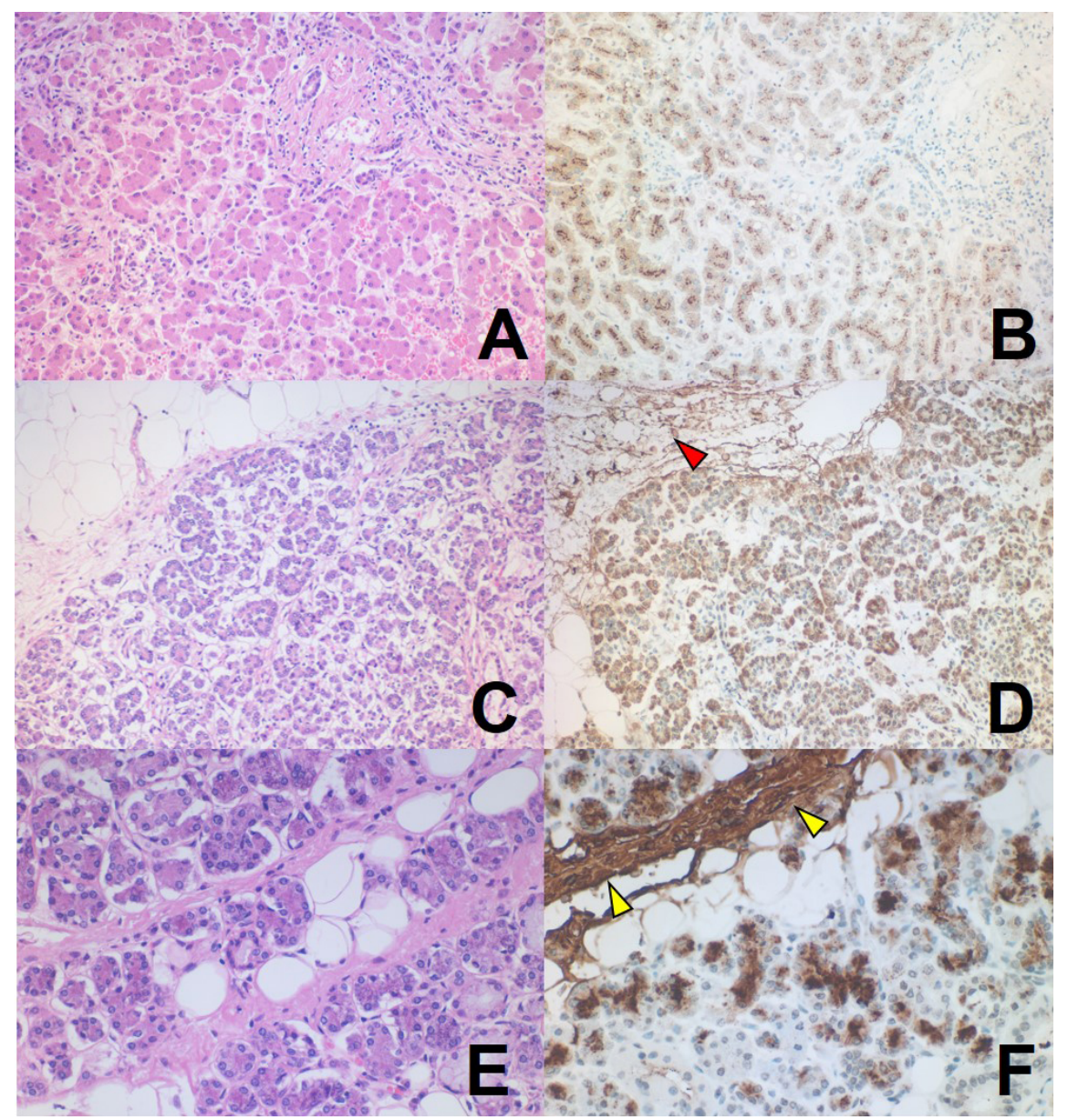

